\title{
Impact of transcatheter aortic valve size on leaflet stresses: implications for durability and optimal grey zone sizing
}

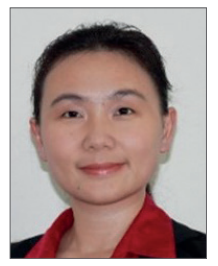

Yue Xuan ${ }^{1}$, PhD; Danny Dvir ${ }^{2}$, MD; Andrew D. Wisneski ${ }^{1}$, MD; Zhongjie Wang ${ }^{1}, \mathrm{PhD}$; Jian $\mathrm{Ye}^{3}$, MD; Julius M. Guccione ${ }^{1}$, PhD; Liang Ge ${ }^{1}, \mathrm{PhD}$; Elaine E. Tseng ${ }^{1 *}$, MD

1. Department of Surgery, University of California San Francisco and San Francisco VA Medical Centers, San Francisco, CA, USA; 2. Division of Cardiology, University of Washington, Seattle, WA, USA; 3. Division of Cardiovascular Surgery, St. Paul's Hospital and Vancouver General Hospital, Vancouver, BC, Canada

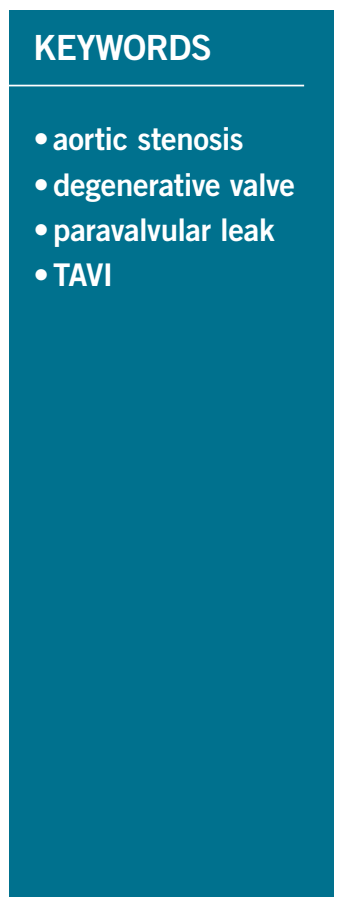

\begin{abstract}
Aims: As indications for transcatheter aortic valve replacement (TAVR) continue to expand towards younger and lower-risk patients, durability becomes an increasingly important question. Durability decreases as leaflet stresses increase, but the impact of transcatheter heart valve (THV) size on stress is unknown. Patient annulus sizes can fall within "grey zones" between 2 TAVR sizes. Our aim was to examine the impact of balloon-expandable THV size on leaflet stresses.
\end{abstract}

Methods and results: SAPIEN XT $23 \mathrm{~mm}, 26 \mathrm{~mm}$, and $29 \mathrm{~mm}$ size valves underwent micro-computed tomography scanning to create THV computational models then loaded to systemic pressure using finite element software. THV leaflet maximum principal stresses were $1.69 \mathrm{MPa}(23 \mathrm{~mm}), 1.70 \mathrm{MPa}(26 \mathrm{~mm})$, and $2.12 \mathrm{MPa}(29 \mathrm{~mm})$ at mean arterial pressure. For intermediate annulus sizes, undersizing the larger THVs yielded lower leaflet stresses than oversizing the smaller THVs.

Conclusions: Increasing THV size yielded greater leaflet maximum principal stresses, which could suggest a relationship between THV size and long-term durability. For annulus "grey zones" sizes, undersizing the larger THV resulted in lower leaflet stresses than oversizing the smaller THV. These results may influence optimal device sizing, as THV durability remains an important, unanswered question.

*Corresponding author: Division of Cardiothoracic Surgery, UCSF Medical Center, 500 Parnassus Ave., Suite 405W, Box 0118, San Francisco, CA, 94143-0118, USA. E-mail: elaine.tseng@ucsf.edu 


\section{Abbreviations}

AS

aortic stenosis

FE finite element

FEA finite element analyses

kPa kilopascal

LVOT left ventricular outflow tract

mm millimeter

MPa megapascal

PVL paravalvular leakage

SAVR surgical aortic valve replacement

TAVR transcatheter aortic valve replacement

THV transcatheter heart valve

\section{Introduction}

Transcatheter aortic valve replacement (TAVR) has revolutionised treatment of severe aortic stenosis (AS) and expanded indications from inoperable and high-risk patients to intermediate-, and potentially soon, to low-risk patients ${ }^{1-5}$. Improving TAVR outcomes by reducing paravalvular leakage (PVL) has required optimal transcatheter heart valve (THV) sizing, which is primarily based on ECG-gated computed tomography angiography (CTA $)^{6-9}$. Selection of the appropriate THV size to implant is based on aortic annulus sizing, which is dynamic, dependent on timing of the cardiac cycle. Timing of CTA image acquisition during diastole vs systole impacts annulus size measurements, and systolic gating to measure maximum annulus area is primarily used for THV size selection ${ }^{8}$. Some patients' annulus sizing falls within areas of "grey zones" between two THV sizes, both of which can be considered appropriate. Clinical decision-making is often guided by parameters such left ventricular outflow tract (LVOT) calcification and risk of annular rupture ${ }^{10}$, anticipation of degree of $\mathrm{PVL}^{6,7,9}$, sinus effacement, and sinotubular junction dimensions.

However, the degree of THV under- or over-sizing impacts the deployed THV shape and leaflet coaptation ${ }^{11,12}$. Such changes in THV configuration can affect leaflet stresses. Prior THV biomechanical studies have suggested that greater leaflet stresses accelerate THV degeneration and limit long term durability ${ }^{13-17}$. There is no method to directly measure leaflet stresses, thus computational methods such as finite element analysis (FEA) are valuable for providing such data, which assess failure modes. Accurate finite element (FE) models require precise 3D geometry in a zerostress state, material properties, and physiologic loading conditions. Our previous FEA studies have determined THV leaflet stresses on specific sizes of first- ${ }^{16}$, second- ${ }^{17}$, and third-generation $^{15}$ SAPIEN, SAPIEN XT, and SAPIEN 3 valves (Edwards Lifsciences Inc., Irvine, CA, USA) under quasi-static loading conditions based on micro-CT images. However, the impact of THV size on THV leaflet stresses is unknown. For each generation of Edwards balloon-expandable THV, there has existed "grey zones" where either of 2 sizes of THV are suitable. Thus, it is helpful to examine leaflet stresses of different sizes of THV and also to understand the impact of under- or oversizing THV within the annular "grey zones."
Edwards SAPIEN XT, a second-generation bovine pericardial balloon-expandable valve, was designed with a cobalt-chromium stent with fewer rows and columns between the commissures compared to the first-generation SAPIEN, allowing reduction in THV profile for smaller delivery systems ${ }^{18}$. In the SAPIEN XT sizing chart, $23 \mathrm{~mm}$ XT was optimal for annulus diameters of 19-22 mm, and areas of 300-380 $\mathrm{mm}^{2}$, while $26 \mathrm{~mm}$ XT was optimal for diameters of 23-25 mm, and areas of $415-490 \mathrm{~mm}^{2}$. As such, a grey zone existed between diameters of $22-23 \mathrm{~mm}$, and areas of $380-415 \mathrm{~mm}^{2}$ in which either size $23 \mathrm{~mm}$ or $26 \mathrm{~mm} \mathrm{XT}$ could be chosen for a given patient. Similarly, $29 \mathrm{~mm}$ XT was optimal for annulus diameters of $26-28 \mathrm{~mm}$, and areas of 530$620 \mathrm{~mm}^{219}$. Thus, between diameters of 25-26 mm, and areas of $490-530 \mathrm{~mm}^{2}$, either $26 \mathrm{~mm}$ or $29 \mathrm{~mm} \mathrm{XT} \mathrm{could} \mathrm{be} \mathrm{chosen} \mathrm{for}$ a patient. Choosing the smaller THV would result in THV oversizing (overexpansion of a smaller sized THV), while choosing the larger THV would result in THV undersizing (underexpansion of a larger sized THV). Based upon the availability of three sizes of commercial SAPIEN XT, our goal in this study was to determine THV leaflet stresses with increasing THV size to understand the impact of choosing a given THV size on future long-term durability using XT THVs as an example.

\section{Materials and methods}

Commercial $23 \mathrm{~mm}, 26 \mathrm{~mm}$, and $29 \mathrm{~mm}$ Edwards SAPIEN XTs were obtained. A fully expanded THV assembly consisted of 3 components: cobalt-chromium stent, Dacron skirt, and bovine pericardial leaflets. Suture connections between different components were included to enable accurate simulation of the assembly with its connections. The process to determine THV stress distribution included: 1) microCT scanning of each individual THV, 2) 3D reconstruction of THV components, 3) FE simulation to mimic in vivo blood pressure and deployment, and 4) post-processing and data analysis to determine stresses on leaflets and stents.

\section{TRANSCATHETER AORTIC VALVE RECONSTRUCTION}

SAPIEN XT valves were imaged with a desktop cone-beam microcomputed tomography scanner (microCT-40; Scanco Medical AG, Baseldorf, Switzerland) in different orientations and intensities to distinguish stent and leaflet geometries as previously described ${ }^{15-17}$. High-resolution DICOM (Digital Imaging and Communications in Medicine) radiologic images were imported into MeVisLab image processing software (MeVis Medical Solutions AG, Bremen, Germany). Images were manually segmented to separate THV stent vs. leaflets and obtain the most accurate representation of each of the three TAVR sizes. Reconstructed geometries were then imported into Geomagic Design $\mathrm{X}^{\circledR}$ (3D Systems, Rock Hill, SC, USA) to create the geometric model, which was used to generate volumetric mesh in TrueGrid ${ }^{\circledR}$ (XYZ Scientific Applications, Inc., Pleasant Hills, CA, USA). Convergence studies were performed to determine optimal mesh density. The mesh was refined until the stress results varied $<5 \%$ for two subsequent mesh refinements ${ }^{20}$. Ultimately, 20,988 elements were chosen for the leaflets on the 
$23 \mathrm{~mm}, 26 \mathrm{~mm}$, and $29 \mathrm{~mm}$ SAPIEN XT valves, 6,336 elements for the stent, and 1,848 elements for the Dacron skirt. Leaflets, stent, and Dacron were precisely reconstructed and aligned to create the entire THV model. Leaflets were attached to the Dacron and stent along suture lines. The geometry and mesh of a representative THV are shown (Figure 1 and Figure 2). Stent geometry was modelled using 3-dimensional brick elements, while leaflet geometry was modelled using nonlinear shell elements.

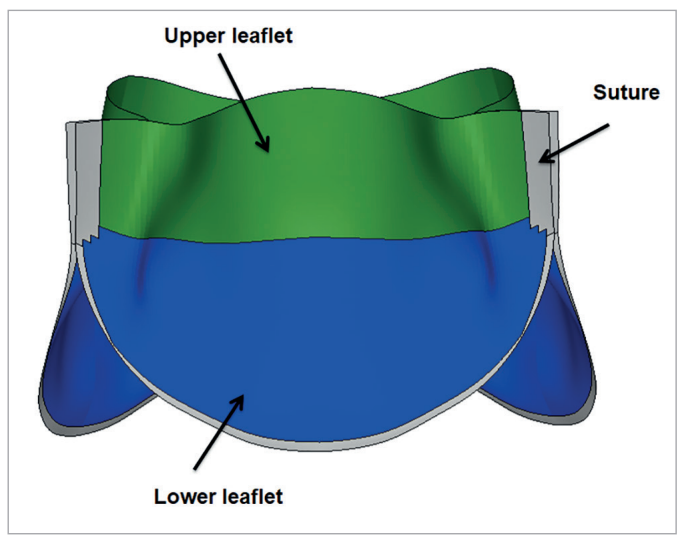

Figure 1.Transcatheter heart valve leaflet assembly. Regions of interest studied for stress distribution in leaflets: upper leaflet free edges; lower leaflet belly; and sutured leaflet edges.

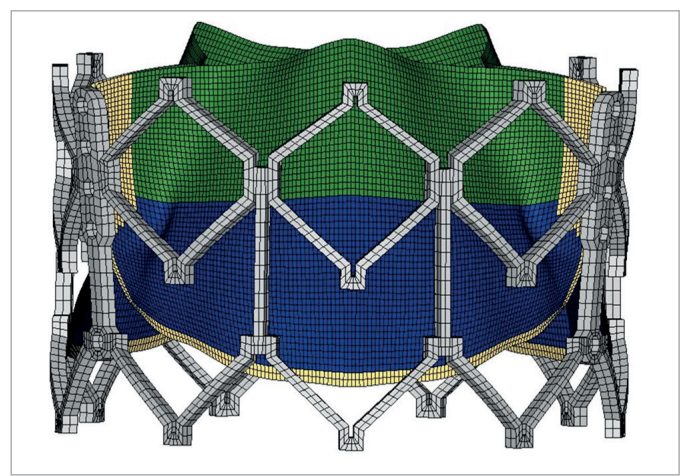

Figure 2. Transcatheter heart valve mesh. Representative mesh of $23 \mathrm{~mm}$ SAPIENXT with leaflet assembly and stent frame.

\section{FINITE ELEMENT ANALYSES}

Deployment and dynamic systemic pressure loading were performed using ABAQUS (Dassault Systems, Waltham, MA, USA). Contact definitions between the pairs of inner leaflets, leaflet and stent, leaflet and Dacron, and stent and Dacron were defined to most accurately represent the contact interaction behaviour. THV leaflet geometries were sutured to the stent at the commissure area and sutured to the Dacron mesh along the bottom edge as seen in Figure 2. Leaflets of the SAPIEN XT valve are composed of bovine pericardium which is specially treated to resist calcification, a proprietary process that is also used for corresponding surgical Carpentier-Edwards Magna pericardial valves (Edwards Lifesciences, Inc.). Biaxial stretch testing of these surgical valve leaflets ( $\mathrm{n}=12$ with 35 valve leaflets) was performed to determine the material properties of THV leaflets ${ }^{21}$ and the constitutive material model was previously described ${ }^{16,17}$. A nonlinear regression Levenberg-Marquardt least squares algorithm in MATLAB (version 2014a, MathWorks, Natick, MA, USA) was used to fit experimentally obtained stresses to find the bestfitting material constants.

Pressure loading was applied to the fully expanded THV at nominal geometry or to the deployed geometry. Superior surfaces of leaflets and all the surfaces of the stent were subjected to dynamic loading of systemic pressures. After the initial pressurisation, cardiac cycles of $800 \mathrm{~ms}$ duration were applied. Each cardiac cycle was composed of a $300 \mathrm{~ms}$ ramp upwards to maximum systolic pressure, followed by a $500 \mathrm{~ms}$ ramp downwards to minimum diastolic pressure.

A repeatability study to verify the stress results was performed and the repeatability was satisfactory. One of the study authors (Z. Wang) independently re-created the models of all three sizes of SAPIEN XT valve from the micro-CT images, and ran pressure loading simulations. Stress distribution on the leaflet and stent of each size was nearly identical to the original model, and variation of the peak stress magnitudes was $6.28 \% \pm 3.84 \%$ (mean $\pm \mathrm{SD}$ ), which was within the range of the previous interobserver study ${ }^{22}$.

\section{Results}

For SAPIEN XT leaflets, the maximum principal stresses across the entire leaflet, including sutured regions, were 1.69 MPa, 1.70 MPa, and $2.12 \mathrm{MPa}$ for $23 \mathrm{~mm}, 26 \mathrm{~mm}$, and $29 \mathrm{~mm} \mathrm{XT}$, respectively, at mean arterial pressure of $93.3 \mathrm{mmHg}$ (Figure 3A-Figure 3C). Minimum principal stresses across the entire leaflet, including sutured regions were $-0.37 \mathrm{MPa},-0.29 \mathrm{MPa}$ and $-0.24 \mathrm{MPa}$ for $23 \mathrm{~mm}, 26 \mathrm{~mm}$, and $29 \mathrm{~mm} \mathrm{XT}$, respectively, at mean arterial pressure (Figure 3D-Figure 3F). Maximum and minimum principal stresses for each region in $23 \mathrm{~mm}, 26 \mathrm{~mm}$, and $29 \mathrm{~mm}$ XT are listed in Table 1. Positive stress values correspond to tensile stress where THV leaflets are stretched to provide coaptation, while negative stress values represent leaflet compression or bending where redundant tissue was compressed in order to coapt. Peak stresses occurred at tips of leaflet commissures along the attachment with the stent in the $23 \mathrm{~mm}$ and $29 \mathrm{~mm}$ XT and occurred at the bottom suture of leaflet to the Dacron in $26 \mathrm{~mm}$ XT (Figure 3). In contrast, regions of free leaflet margin at the top and leaflet belly at the bottom had lower peak stresses for all three sizes.

Stress distribution on leaflets of each THV size was analysed and plotted on histograms (Figure 4). Surface areas of each leaflet were $304 \mathrm{~mm}^{2}, 338 \mathrm{~mm}^{2}$, and $392 \mathrm{~mm}^{2}$ for $23 \mathrm{~mm}, 26 \mathrm{~mm}$, and $29 \mathrm{~mm}$ $\mathrm{XT}$, respectively. Median values of maximum principal stresses were $0.32 \mathrm{MPa}, 0.35 \mathrm{MPa}$, and $0.41 \mathrm{MPa}$ with increasing THV size, $23 \mathrm{~mm}, 26 \mathrm{~mm}$, and $29 \mathrm{~mm}$ XT, respectively. Examining the most frequent leaflet stress values by histogram, they fell within the range of [300, 400], [400, 500] and [500, 600] kPa for the $23 \mathrm{~mm}, 26 \mathrm{~mm}$, and $29 \mathrm{~mm} \mathrm{XT}$, respectively (Figure 4). 


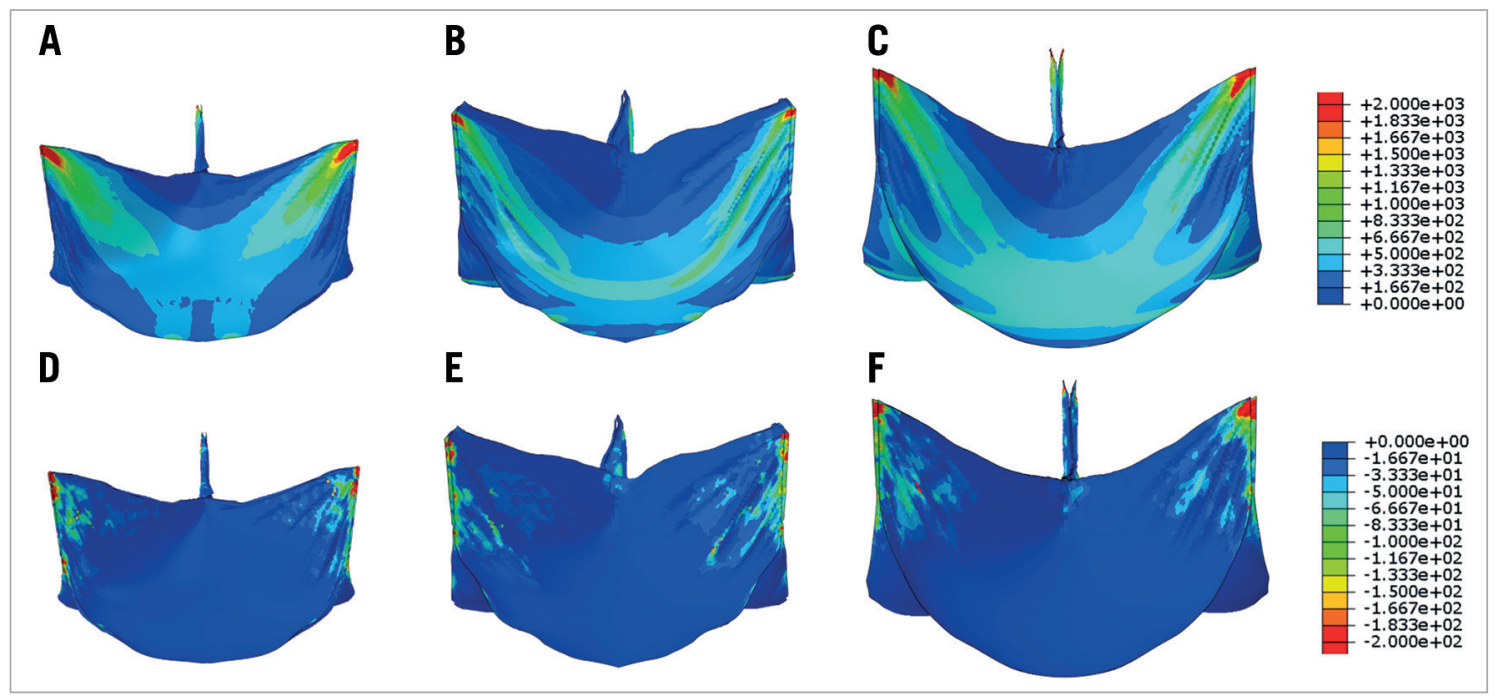

Figure 3. Maximum and minimum principal stresses on transcatheter heart valve leaflets. Maximum (A-C) and minimum (D-F) principal stresses on entire leaflet of $23 \mathrm{~mm}, 26 \mathrm{~mm}$, and $29 \mathrm{~mm}$ SAPIEN XT at mean arterial pressure.

Table 1. Maximum and minimum principal stresses of transcatheter heart valve subregions by size.

\begin{tabular}{|l|c|c|c|c|c|c|}
\hline \multirow{2}{*}{} & \multicolumn{3}{|c|}{ Max. principal stress (MPa) } & \multicolumn{3}{c|}{ Min. principal stress } \\
\cline { 2 - 7 } & 23XT & 26XT & 29XT & 23XT & 26XT & 29XT \\
\hline Upper leaflet & 1.69 & 1.43 & 2.12 & -0.17 & -0.13 & -0.24 \\
\hline Lower leaflet & 0.77 & 1.61 & 1.11 & -0.15 & -0.20 & -0.11 \\
\hline Leaflet Sutured Region & 1.14 & 1.70 & 1.66 & -0.37 & -0.29 & -0.20 \\
\hline Stent & 54.91 & 47.33 & 53.11 & -52.12 & -48.78 & -50.71 \\
\hline MPa: megapascal & \multicolumn{7}{|l|}{} \\
\hline
\end{tabular}
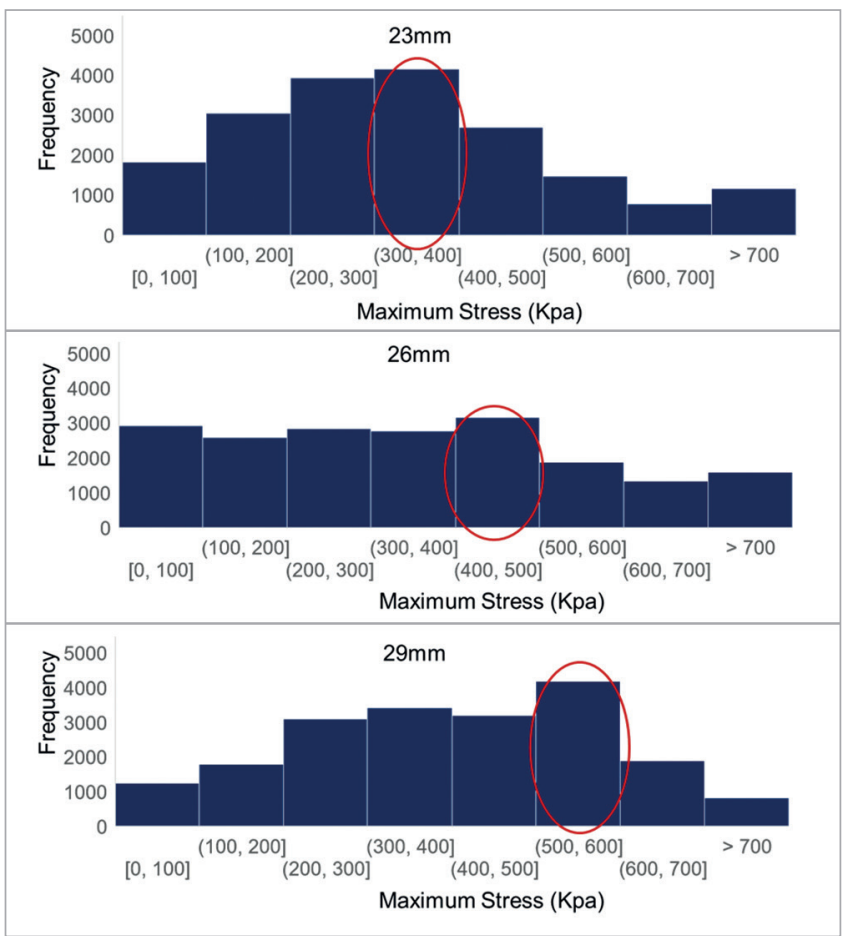

Figure 4. Histogram of leaflet stress values. Histogram of leaflet stress distribution for three SAPIEN XT sizes. Circled bar indicates range with highest frequency.
To determine THV leaflet stresses for annulus sizes within the grey zones, we deployed $23 \mathrm{~mm}$ and $26 \mathrm{~mm}$ XT valves within an annulus of area $398 \mathrm{~mm}^{2}$, which clinically would require balloon oversizing the $23 \mathrm{~mm} \mathrm{XT}$ and undersizing the $26 \mathrm{~mm} \mathrm{XT}$. When deployed within the same size annulus, leaflet stresses were compared. Stress distribution in the undersized $26 \mathrm{~mm}$ XT was greatly shifted towards lower stress levels (Figure 5), while stress distribution in the oversized $23 \mathrm{~mm}$ XT did not change significantly from its fully expanded position and overall, had higher frequencies of high stress concentrations than the $26 \mathrm{~mm}$ XT valve. Similarly, we deployed the $26 \mathrm{~mm}$ and $29 \mathrm{~mm}$ XT valves within grey zone of annulus area $511 \mathrm{~mm}^{2}$. Leaflet stresses on the undersized $29 \mathrm{~mm}$ XT again were greatly shifted towards lower stress levels (Figure 6), while the oversized $26 \mathrm{~mm}$ XT showed minimal change in stresses from its nominal geometry, but overall had higher frequencies of larger stress concentrations than the undersized $29 \mathrm{~mm}$ XT valve.

For the SAPIEN XT stent, maximum principal stresses at mean arterial pressure were $54.91 \mathrm{MPa}, 47.33 \mathrm{MPa}$, and $53.11 \mathrm{MPa}$, for $23 \mathrm{~mm}, 26 \mathrm{~mm}$, and $29 \mathrm{~mm} \mathrm{XT}$, respectively; minimum principal stresses at mean arterial pressure were $-52.12 \mathrm{MPa},-48.78 \mathrm{MPa}$, and $-50.17 \mathrm{MPa}$, for $23 \mathrm{~mm}, 26 \mathrm{~mm}$, and $29 \mathrm{~mm} \mathrm{XT}$, respectively (Figure 7). Peak stresses occurred on the stent in proximity to the simulated patient annulus and at distal frame elements. 


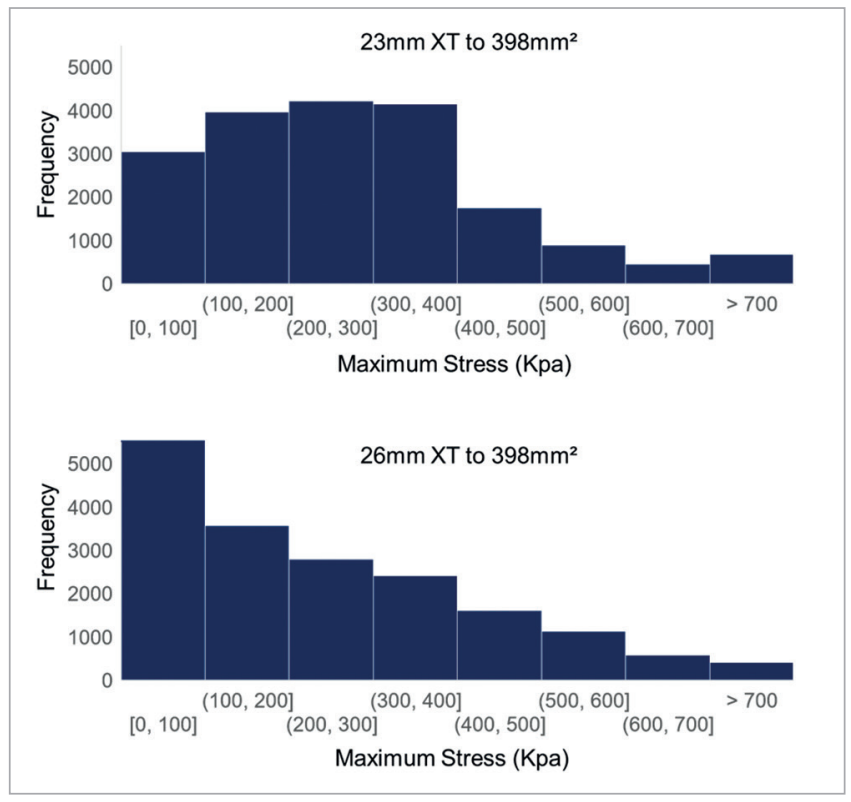

Figure 5. Leaflet stress histogram for $23 \mathrm{~mm}$ and $26 \mathrm{~mm}$ SAPIEN XT deployed to $398 \mathrm{~mm}^{2}$. Histogram of stress distribution on leaflets of $23 \mathrm{~mm}$ and $26 \mathrm{~mm}$ SAPIEN XT deployed to $398 \mathrm{~mm}^{2}$. The $y$-axis value represents the number of elements in the model experiencing the specified range of stress defined by the $x$-axis bin-width.

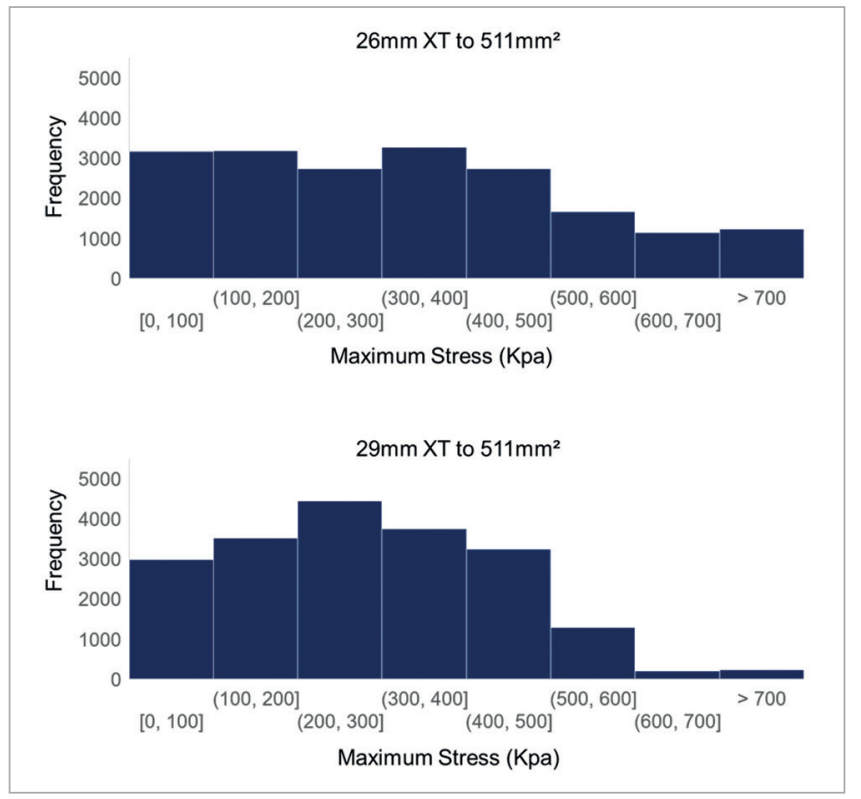

Figure 6. Leaflet stress histogram for $26 \mathrm{~mm}$ and $29 \mathrm{~mm}$ SAPIEN XT deployed to $511 \mathrm{~mm}^{2}$. Histogram of stress distribution on leaflets of $26 \mathrm{~mm}$ and $29 \mathrm{~mm}$ SAPIEN XT deployed to $511 \mathrm{~mm}^{2}$. The y-axis value represents the number of elements in the model experiencing the specified range of stress defined by the $x$-axis bin-width.

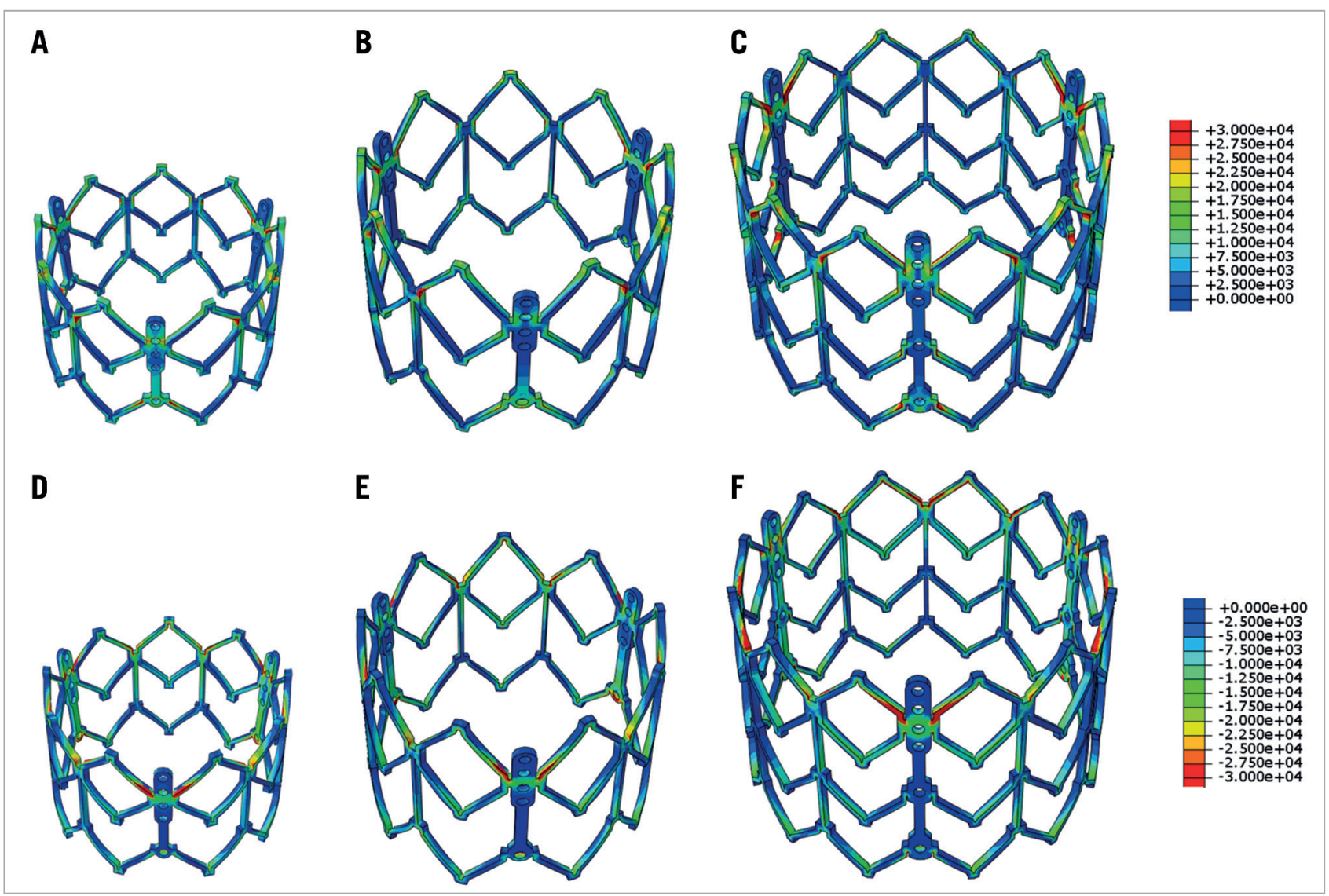

Figure 7. Maximum and minimum principal stress on transcatheter heart valve stent. Maximum (A6C) and minimum (dD6F) principal stresses of stent of $23 \mathrm{~mm}, 26 \mathrm{~mm}$, and $29 \mathrm{~mm}$ SAPIEN XT at mean arterial pressure. 


\section{Discussion}

Edwards balloon-expandable THVs, approved by the US Food and Drug Administration in late 2011, have revealed no structural valve dysfunction with maintenance of low gradients and excellent valve area at five years ${ }^{4}$. While short-term durability appears adequate, long-term follow-up for durability of these valve designs is needed. Biomechanical studies using FEA can provide insight into mechanisms of valve degeneration by non-invasive approaches. Our current study investigated the impact of THV size from the same generation of balloon-expandable THVs on leaflet and stent stresses, which may impact bioprosthetic valve durability. Stresses on leaflets and stents of three different sizes of SAPIEN XT were computationally determined and compared. Our study established the benchmark to access the size effect on the long-term durability of bioprosthetic THVs, as indications for TAVR continue to expand to lower risk and younger patient populations.

\section{PEAK STRESS AND SIZE}

Three different sizes of second-generation SAPIEN XT valve were available for different annulus dimensions. Commonly, patient annulus areas can fall into the grey zone between two THV sizes. In this study, peak stresses on THV leaflets, irrespective of region, increased with increasing THV size when examining THVs expanded to nominal dimension. Overall, median stresses for the entire leaflet increased with increasing THV size at nominal, fully expanded deployment states (Figure 5). This is explained by the in-plane force being roughly equal to the product of pressure and cross-sectional area. Thus, a larger valve has greater total force on the leaflets because of its larger cross-sectional area for the same pressure loading. Our results suggest that THV size selection may potentially impact long-term durability.

\section{OPTIMAL TAVR SIZING}

Clinically, optimal TAVR sizing balances ideal haemodynamics with risks, such as conduction disorders and annular rupture. From a haemodynamics standpoint, larger TAVR size minimises transvalvular gradient and PVL, and maximises effective orifice area to decrease patient-prosthesis mismatch. PVL results from lack of congruence between annulus and THV, and is related to undersized THV prosthesis, device malpositioning, heavily calcified bulky native aortic valve cusps, and/or bicuspid valve ${ }^{23}$. Larger baseline annular coronal and oblique sagittal dimensions were found in patients with significant $\mathrm{PVL}^{24}$. Low cover index was also associated with PVL, suggesting that THV oversizing was necessary to reduce PVL ${ }^{25}$. From a patient-prosthesis standpoint, a larger THV size leads to less patient-prosthesis mismatch ${ }^{26}$, which affects mortality ${ }^{27}$. On the other hand, oversizing a THV can compress the conduction system, increase the rate of permanent pacemaker implantation, and increase risk of annular rupture when LVOT calcification is present ${ }^{25}$.

In this study, we examined the impact of oversizing a smaller THV vs undersizing a larger THV for annulus sizes within the grey zone, and examined differences in leaflet stresses as a potential indicator for long-term durability. Undersizing the larger THV led to significantly lower leaflet stresses than oversizing the smaller THV, which may be another clinical consideration when choosing between two TAVR sizes. Overall, for annulus sizes that were clearly within the $23 \mathrm{~mm}, 26 \mathrm{~mm}$, or $29 \mathrm{~mm}$ XT sizing guidelines, the larger THV had higher peak stresses which may lead to earlier THV bioprosthetic degeneration. In comparison, other computational studies examined how THV underexpansion affects leaflet stress, concluding that peak leaflet stress increased with more underexpansion ${ }^{12,28}$. For a given THV size, greater degrees of underexpansion were unfavorable compared to nominal deployment ${ }^{12,28}$. However, in these prior studies, only one THV size was tested with varying degrees of underexpansion, and did not account for an alternative THV size option for a given annulus size.

TAVR physicians must exercise their best judgment when choosing the optimal THV size within the grey zones based upon current practices, the finite number of THV sizes available, patient anatomy, including LVOT calcification, sinus effacement, and sinotubular junction dimensions, as well as optimal haemodynamics minimising PVL, to achieve ideal clinical outcomes. With multifactorial risk factors for bioprosthetic valve degeneration, choosing the THV size based upon leaflet stresses to optimise long-term durability is yet one additional procedural consideration that could be factored into clinical decision-making to offer the benefit of longevity. Further clinical study will be needed to correlate calculated leaflet stress results with valve durability and loss of collagen integrity.

\section{Limitations}

The $23 \mathrm{~mm}, 26 \mathrm{~mm}$, and $29 \mathrm{~mm}$ SAPIEN XT valves were chosen for controlled comparisons within one generation of balloonexpandable THV to investigate the impact of size on THV leaflet stresses. Given that the limited access to THVs for research purposes, complete sizes of SAPIEN 3 valves were not available to conduct this study. Given the SAPIEN 3 also has grey zones that accept either an oversized smaller THV or an undersized larger THV, these computational simulations examining leaflet stresses in a similar leaflet design across sizes are still translatable clinically. This study did not take into account leaflet damage from the crimping and ballooning process which occurs during TAVR. Studies have demonstrated that crimping physically damages THV leaflets and may weaken leaflets and increase leaflet stresses ${ }^{1}$. We did not destroy our THVs to test their leaflets for exact material properties given the rarity of obtaining THVs and the need for future TAVR experimental in vitro testing which were beyond the scope of this study. As such, we utilised excised leaflets from surgical bioprostheses to determine material properties for THV leaflets. While treatment processes for both Edwards valves are expected to be the same, thinner pericardial leaflets used in TAVR may have slightly different material properties ${ }^{6}$ than were represented here. As stent and leaflet stresses cannot be directly measured, there was no suitable method to perform experimental validation of stresses. Complex fluid-structure interaction simulations were not incorporated and were beyond the present scope of this study. Lastly, patient-specific 
simulations of each of the THV sizes were not performed, given that a single patient would only be able to provide a post-TAVR CT of one THV size and not yield suitable information regarding the second THV size when choosing between two sizes.

\section{Conclusions}

We studied the impact of balloon-expandable THV size on leaflet and stent stress in this study by comparing the same generation of THV with three available sizes. Larger THV sizes had greater leaflet stresses and may be more prone to earlier degeneration. On the other hand, when choosing between two THV sizes within the grey zones of annulus sizing, undersizing the larger TAVR resulted in lower leaflet stresses than oversizing the smaller THV. Sizing THVs currently takes into account annular measurements from CTA, as well as potential for PVL, patient-prosthesis mismatch, and risk of permanent pacemaker implantation and annular rupture. The results from this study shed light on another factor, leaflet stresses and THV size. Correlation with further clinical studies will be essential to correlate stresses with valve durability.

\section{Impact on daily practice}

For some patients, the measured annulus size falls within the grey zone of THV sizing and is suitable for two THV sizes, depending on the degree of oversizing/undersizing. We performed finite element analyses of $23 \mathrm{~mm}, 26 \mathrm{~mm}$, and $29 \mathrm{~mm}$ second-generation balloon-expandable THVs to determine the impact of device size on leaflet stresses, as a surrogate for durability. Larger THV sizes had higher peak leaflet stresses. However, for annulus sizes within the grey zone between two THV sizes, stresses were reduced when using an undersized larger THV than oversized smaller THV deployed in the same annulus size. The choice to size upwards in the grey zone may lead to improved long-term valve durability.

\section{Funding}

The study was funded by the University of California Proof of Concept grant \#246590, National Institutes of Health R01HL119857, and American Heart Association Postdoctoral Fellowship 16POST31420013.

\section{Conflict of interest statement}

E. Tseng and L.Ge are founders of ReValve Med, Inc. D. Dvir and J. Ye are consultants for Edwards Lifesciences. The other authors have no conflicts of interest to declare.

\section{References}

1. Deeb GM, Reardon MJ, Chetcuti S, Patel HJ, Grossman PM, Yakubov SJ, Kleiman NS, Coselli JS, Gleason TG, Lee JS, Hermiller JB, Jr., Heiser J, Merhi W, Zorn GL, 3rd, Tadros P, Robinson N, Petrossian G, Hughes GC, Harrison JK, Maini B, Mumtaz M, Conte J, Resar J, Aharonian V, Pfeffer T, Oh JK, Qiao H, Adams DH, Popma JJ. 3-year outcomes in high-risk patients who underwent surgical or transcatheter aortic valve replacement. J Am Coll Cardiol. 2016;67:2565-74.

2. Grover FL, Vemulapalli S, Carroll JD, Edwards FH, Mack MJ, Thourani VH, Brindis RG, Shahian DM, Ruiz CE, Jacobs JP, Hanzel G, Bavaria JE, Tuzcu EM, Peterson ED, Fitzgerald S, Kourtis M, Michaels J, Christensen B, Seward WF, Hewitt K, Holmes DR, Jr; STS/ACC TVT Registry. 016 Annual Report of The Society of Thoracic Surgeons/American College of Cardiology Transcatheter Valve Therapy Registry. J Am Coll Cardiol. 2017; 69:1215-30.

3. Kapadia SR, Leon MB, Makkar RR, Tuzcu EM, Svensson LG, Kodali S, Webb JG, Mack MJ, Douglas PS, Thourani VH, Babaliaros VC, Herrmann HC, Szeto WY, Pichard AD, Williams MR, Fontana GP, Miller DC, Anderson WN, Akin JJ, Davidson MJ, Smith CR; PARTNER trial investigators. 5-year outcomes of transcatheter aortic valve replacement compared with standard treatment for patients with inoperable aortic stenosis (PARTNER 1): A randomised controlled trial. Lancet. 2015; 385:2485-91.

4. Mack MJ, Leon MB, Smith CR, Miller DC, Moses JW, Tuzcu EM, Webb JG, Douglas PS, Anderson WN, Blackstone EH, Kodali SK, Makkar RR, Fontana GP, Kapadia S, Bavaria J, Hahn RT, Thourani VH, Babaliaros V, Pichard A, Herrmann HC, Brown DL, Williams M, Davidson MJ, Svensson LG, Akin J; PARTNER 1 trial investigators. 5-year outcomes of transcatheter aortic valve replacement or surgical aortic valve replacement for high surgical risk patients with aortic stenosis (PARTNER 1): A randomised controlled trial. Lancet. 2015;385:2477-84.

5. Nishimura RA, Otto CM, Bonow RO, Carabello BA, Erwin JP 3rd, Fleisher LA, Jneid H, Mack MJ, McLeod CJ, O'Gara PT, Rigolin VH, Sundt TM 3rd, Thompson A. 2017 AHA/ACC Focused Update of the 2014 AHA/ACC Guideline for the Management of Patients With Valvular Heart Disease: A Report of the American College of Cardiology/American Heart Association Task Force on Clinical Practice Guidelines. J Am Coll Cardiol. 2017;70:252-89.

6. Leber AW, Eichinger W, Rieber J, Lieber M, Schleger S, Ebersberger U, Deichstetter M, Vogel J, Helmberger T, Antoni D, Riess G, Hoffmann E, Kasel AM. MSCT guided sizing of the Edwards Sapien XT TAVI device: impact of different degrees of oversizing on clinical outcome. Int J Cardiol. 2013;168:2658-64.

7. Stähli BE, Nguyen-Kim TD, Gebhard C, Erhart L, Frauenfelder T, Tanner FC, Falk V, Landmesser U, Nietlispach F, Lüscher TF, Maier W, Binder RK. Prosthesis-Specific Predictors of Paravalvular Regurgitation after Transcatheter Aortic Valve Replacement: Impact of Calcification and Sizing on Balloon-Expandable versus Self-Expandable Transcatheter Heart Valves. J Heart Valve Dis. 2015;24:10-21.

8. Murphy DT, Blanke P, Alaamri S, Naoum C, Rubinshtein R, Pache G, Precious B, Berger A, Raju R, Dvir D, Wood DA, Webb J, Leipsic JA. Dynamism of the aortic annulus: Effect of diastolic versus systolic CT annular measurements on device selection in transcatheter aortic valve replacement (TAVR). J Cardiovasc Comput Tomogr. 2016;10:37-43. 
9. Binder RK, Webb JG, Willson AB, Urena M, Hansson NC, Norgaard BL, Pibarot P, Barbanti M, Larose E, Freeman M, Dumont E, Thompson C, Wheeler M, Moss RR, Yang TH, Pasian S, Hague CJ, Nguyen G, Raju R, Toggweiler S, Min JK, Wood DA, Rodés-Cabau J, Leipsic J. The impact of integration of a multidetector computed tomography annulus area sizing algorithm on outcomes of transcatheter aortic valve replacement: a prospective, multicenter, controlled trial. J Am Coll Cardiol. 2013;62:431-8.

10. Barbanti M, Yang TH, Rodès Cabau J, Tamburino C, Wood DA, Jilaihawi H, Blanke P, Makkar RR, Latib A, Colombo A, Tarantini G, Raju R, Binder RK, Nguyen G, Freeman M, Ribeiro HB, Kapadia S, Min J, Feuchtner G, Gurtvich R, Alqoofi F, Pelletier M, Ussia GP, Napodano M, de Brito FS Jr, Kodali S, Norgaard BL, Hansson NC, Pache G, Canovas SJ, Zhang H, Leon MB, Webb JG, Leipsic J. Anatomical and procedural features associated with aortic root rupture during balloon-expandable transcatheter aortic valve replacement. Circulation. 2013;128:244-53.

11. Sun W, Li K, Sirois E. Simulated elliptical bioprosthetic valve deformation: Implications for asymmetric transcatheter valve deployment. J Biomech. 2010;43:3085-90.

12. Abbasi M, Azadani AN. Leaflet stress and strain distributions following incomplete transcatheter aortic valve expansion. J Biomech. 2015;48:3663-71.

13. Martin C, Sun W. Comparison of transcatheter aortic valve and surgical bioprosthetic valve durability: A fatigue simulation study. J Biomech. 2015;48:3026-34.

14. Martin C, Sun W. Simulation of long-term fatigue damage in bioprosthetic heart valves: effects of leaflet and stent elastic properties. Biomech Model Mechanobiol. 2014;13:759-70.

15. Xuan Y, Dvir D, Wang Z, Mizoguchi T, Ye J, Guccione JM, Ge L, Tseng EE. Stent and leaflet stresses in 26-mm, third-generation, balloon-expandable transcatheter aortic valve. $J$ Thorac Cardiovasc Surg. 2019;157:528-36.

16. Xuan Y, Krishnan K, Ye J, Dvir D, Guccione JM, Ge L, Tseng EE. Stent and leaflet stresses in a 26-mm first-generation balloon-expandable transcatheter aortic valve. J Thorac Cardiovasc Surg. 2017;153:1065-73.

17. Xuan Y, Krishnan K, Ye J, Dvir D, Guccione JM, Ge L, Tseng EE. Stent and leaflet stresses in 29-mm second-generation balloon-expandable transcatheter aortic valve. Ann Thorac Surg. 2017;104:773-81.

18. Rodes-Cabau J. Transcatheter aortic valve implantation: current and future approaches. Nat Rev Cardiol. 2011;9:15-29.

19. U. S. Food and Drug Administration(2014).Edwards SAPIEN XT Transcatheter Heart Valve with the Ascendra+ Delivery System. https://www.accessdata.fda.gov/cdrh_docs/pdf13/P130009d.pdf
20. Sinclair GB, Beisheim JR, Sezer S. Practical convergencedivergence checks for stresses from FEA.Proccedings of the 2006 International ANSYS Conference, Pittsburgh, PA, USA, 2-4 May 2006; MIT Press, Cambridge, MA, USA.

21. Azadani AN, Chitsaz S, Matthews PB, Jaussaud N, Leung J, Tsinman T, Ge L, Tseng EE. Comparison of mechanical properties of human ascending aorta and aortic sinuses. Ann Thorac Surg. 2012;93:87-94.

22. Teutelink A, Cancrinus E, van de Heuvel D, Moll F, de Vries JP. Preliminary intraobserver and interobserver variability in wall stress and rupture risk assessment of abdominal aortic aneurysms using a semiautomatic finite element model. J Vasc Surg. 2012;55: 326-30.

23. Zegdi R, Ciobotaru V, Noghin M, Sleilaty G, Lafont A, Latremouille C, Deloche A, Fabiani JN. Is it reasonable to treat all calcified stenotic aortic valves with a valved stent? Results from a human anatomic study in adults. J Am Coll Cardiol. 2008;51: 579-84.

24. Delgado V, Ng AC, van de Veire NR, van der Kley F, Schuijf JD, Tops LF, de Weger A, Tavilla G, de Roos A, Kroft LJ, Schalij MJ, Bax JJ. Transcatheter aortic valve implantation: Role of multidetector row computed tomography to evaluate prosthesis positioning and deployment in relation to valve function. Eur Heart $J$. 2010;31:1114-23.

25. Détaint D, Lepage L, Himbert D, Brochet E, Messika-Zeitoun D, Iung B, Vahanian A. Determinants of significant paravalvular regurgitation after transcatheter aortic valve: implantation impact of device and annulus discongruence. JACC Cardiovasc Interv. 2009;2:821-7.

26. Deeb GM, Chetcuti SJ, Yakubov SJ, Patel HJ, Grossman PM, Kleiman NS, Heiser J, Merhi W, Zorn GL, 3rd, Tadros PN, Petrossian G, Robinson N, Mumtaz M, Gleason TG, Huang J, Conte JV, Popma JJ, Reardon MJ. Impact of annular size on outcomes after surgical or transcatheter aortic valve replacement. Ann Thorac Surg. 2018;105:1129-36.

27. Pibarot P, Weissman NJ, Stewart WJ, Hahn RT, Lindman BR, McAndrew T, Kodali SK, Mack MJ, Thourani VH, Miller DC, Svensson LG, Herrmann HC, Smith CR, Rodés-Cabau J, Webb J, Lim S, Xu K, Hueter I, Douglas PS, Leon MB. Incidence and sequelae of prosthesis-patient mismatch in transcatheter versus surgical valve replacement in high-risk patients with severe aortic stenosis: a PARTNER trial cohort--a analysis. J Am Coll Cardiol. 2014;64:1323-34.

28. Martin C, Sun W. Transcatheter Valve Underexpansion Limits Leaflet Durability: Implications for Valve-in-Valve Procedures. Ann Biomed Eng. 2017;45:394-404. 